\title{
Plasma concentrations of adrenomedullin correlate with the extent of pulmonary hypertension in patients with mitral stenosis
}

Toshio Nishikimi, Seiki Nagata, Tatsuya Sasaki, Shigehiro Tomimoto, Hiroaki Matsuoka, Shuichi Takishita, Kazuo Kitamura, Atsuro Miyata, Hisayuki Matsuo, Kenji Kangawa

\begin{abstract}
Objective-To examine the pathophysiological significance of adrenomedullin in the pulmonary circulation by investigating the relation between plasma concentrations of adrenomedullin and central haemodynamics in patients with mitral stenosis.

Methods-Plasma concentrations of adrenomedullin in blood samples obtained from the femoral vein, pulmonary artery, left atrium, and aorta were measured by a newly developed specific radioimmunoassay in 23 consecutive patients with mitral stenosis (16 females and seven males, aged 53 (10) years (mean (SD)) who were undergoing percutaneous mitral commissurotomy.

Results-Patients with mitral stenosis had higher concentrations of adrenomedullin than age matched normal controls (3.9 (0.3) v $2.5(0.3) \mathrm{pmol} / 1, \quad \mathrm{p}<0.001)$. There was a reduction in adrenomedullin concentrations between the pulmonary artery and the left atrium (3.8 (0.2) v $3.2(0.4) \mathrm{pmol} / 1, \mathrm{p}<0.001)$. The venous concentrations of adrenomedullin correlated with mean pulmonary artery pressure $(r=0.65, \mathrm{p}<0.001)$, total pulmonary vascular resistance $(r=0.83, \mathrm{p}<0.0001)$, and pulmonary vascular resistance $(r=0.65, p<0.001)$. Plasma concentrations of adrenomedullin did not change immediately after percutaneous mitral commissurotomy; however, they decreased significantly one week later.

Conclusions-Plasma concentrations of adrenomedullin are increased in patients with mitral stenosis. This may help to attenuate the increased pulmonary arterial resistance in secondary pulmonary hypertension due to mitral stenosis.

(Heart 1997;78:390-395)
\end{abstract}

Keywords: adrenomedullin; pulmonary hypertension; mitral stenosis; pulmonary circulation

The 52-residue vasoactive peptide adrenomedullin, first isolated from human phaeochromocytoma, has an intramolecular disulphide bridge forming a ring structure of six residues and a carboxy terminal amidated residue. ${ }^{1}$ When adrenomedullin is given to rats it produces potent and long lasting hypotensive effects, as powerful as those of calcitonin gene related peptide (CGRP), which is one of the most potent vasorelaxant peptides known. ${ }^{1}$ Immunoreactive adrenomedullin has been detected in human plasma by a specific radioimmunoassay, and raised plasma concentrations of adrenomedullin have been reported in patients with systemic hypertension, chronic renal failure, and heart failure..$^{2-6}$ Recent reports have shown that vascular smooth muscle cells possess specific adrenomedullin receptors that are functionally coupled to adenylate cyclase. $^{78} \mathrm{~A}$ nitric oxide-cyclic guanosine monophosphate mechanism may also be involved in the regional vasculature. ${ }^{9}{ }^{10}$ Furthermore, Nakamura et $a l^{11}$ recently reported that adrenomedullin had approximately 10-fold and 200-fold greater vasodilator potency than sodium nitroprusside and acetylcholine, respectively, when infused into the brachial artery in humans. These findings suggest that adrenomedullin may play a role in the control of the circulation.

Adrenomedullin mRNA is reportedly highly expressed in the adrenal gland, lung, kidney, heart, and vascular walls. ${ }^{12}{ }^{13}$ We previously reported that circulating adrenomedullin is partially metabolised in the lung, ${ }^{14}$ which suggests an abundance of adrenomedullin receptors in the lung. This was recently supported by the finding that the adrenomedullin receptor gene is highly expressed in rat lung. ${ }^{15}$ In addition, high plasma adrenomedullin has been reported in rats with experimentally induced pulmonary hypertension ${ }^{16}$ and in patients with pulmonary hypertension. ${ }^{17}$ Adrenomedullin has been shown to dilate the pulmonary vessels and increase pulmonary blood flow. ${ }^{18} 19$ These findings suggest that adrenomedullin may participate in the control of the pulmonary circulation.

Mitral stenosis is associated with increases in pulmonary artery pressure and resistance. Vasoactive substances such as endothelin and catecholamines have been linked to this disorder. ${ }^{20-22}$ Our study was designed to examine the pathophysiological significance of adrenomedullin in the pulmonary circulation in mitral stenosis. To that end, we measured plasma adrenomedullin in the femoral vein, pulmonary artery, left atrium, and the aorta from 23 consecutive patients with rheumatic mitral stenosis who were undergoing percutaneous transvenous mitral commissurotomy (PTMC). We also simultaneously measured plasma concentrations of atrial natriuretic
Accepted for publication 9 July 1997 
Table 1 Characteristics of the patients

\begin{tabular}{lc}
\hline Age (years) & $53 \quad(10)$ \\
Sex $($ female/male) & $16 / 7 \quad 1.54(0.14)$ \\
BSA $\left(\mathrm{m}^{2}\right)$ & $49.0 \quad(14.0)$ \\
Serum creatinine $(\mu \mathrm{mol} / \mathrm{l})$ & \\
NYHA & 20 \\
$\quad$ Class II & 3 \\
$\quad$ Class III & \\
Rhythm & 7 \\
$\quad$ Sinus & 16 \\
$\quad$ Atrial fibrillation & 6 \\
Previous heart failure & 2 \\
Previous embolism & \\
Drugs & 9 \\
$\quad$ Frusemide & 17 \\
$\quad$ Digoxin &
\end{tabular}

Values are means (SD).

BSA, body surface area; NYHA, New York Heart Association heart failure classification; $\mathrm{CHF}$, congestive heart failure.

factor (ANF) and brain natriuretic peptide (BNP) and compared them with plasma adrenomedullin to characterise this peptide.

\section{Methods}

PATIENTS

Twenty three consecutive symptomatic Japanese patients with mitral stenosis (16 females and seven males aged 38 to 70 years; mean (SD) age 53 (10) years) who underwent PTMC were enrolled in the study. Sixteen patients had atrial fibrillation, and seven were in sinus rhythm. Six had history of right sided heart failure. All the patients had transthoracic echocardiograms and their left ventricular function was normal. Informed consent was obtained from each patient. The characteristics of the patients are given in table 1. All the patients had transoesophageal echocardiograms and patients with left atrial thrombus and those with severe mitral regurgitation (more than grade 2/4) were excluded from study, as were patients with diabetes mellitus, chronic renal failure, and hepatic insufficiency.

CARDIAC CATHETERISATION AND PTMC

All patients underwent right and left sided heart catheterisation before and after PTMC. PTMC was performed with an Inoue balloon catheter by the transseptal Brockenbrough method. ${ }^{2123} 24$ Haemodynamic variables, including pressure in the pulmonary artery, left atrium, left ventricle, and aorta, and the cardiac index were measured before and 20 minutes after the balloon inflation. Left atrial pressure and left ventricular pressure were recorded simultaneously to determine the mean transmitral gradient. Cardiac output was determined by the thermodilution method. Systemic vascular resistance, total pulmonary

Table 2 Haemodynamic variables before and after percutaneous mitral commissurotomy

\begin{tabular}{|c|c|c|c|}
\hline Variable & Before & After & $p$ value \\
\hline Mean pulmonary artery pressure $(\mathrm{mm} \mathrm{Hg})$ & $25.1(7.1)$ & $19.1(5.8)$ & $<0.001$ \\
\hline Left atrial pressure $(\mathrm{mm} \mathrm{Hg})$ & $16.2(5.2)$ & $11.9(5.1)$ & $<0.001$ \\
\hline LVEDP ( $\mathrm{mm} \mathrm{Hg}$ ) & $7.6(4.5)$ & $6.4(4.1)$ & NS \\
\hline Mitral valve area $\left(\mathrm{cm}^{2}\right)$ & $1.38(0.38)$ & $1.75(0.42)$ & $<0.001$ \\
\hline Total pulmonary resistance (dyne.s. $\mathrm{cm}^{-5} \cdot \mathrm{m}^{2}$ ) & $464(147)$ & $358(102)$ & $<0.002$ \\
\hline Pulmonary vascular resistance $\left(\right.$ dyne.s. $\left.\mathrm{cm}^{-5} \cdot \mathrm{m}^{2}\right)$ & $237(103)$ & $207(76)$ & NS \\
\hline Cardiac index $\left(1 / \mathrm{min} \cdot \mathrm{m}^{2}\right)$ & $3.05(0.53)$ & $2.97(0.54)$ & NS \\
\hline Heart rate (beats/min) & $78(16)$ & $74(13)$ & NS \\
\hline Mean arterial pressure $(\mathrm{mm} \mathrm{Hg})$ & $91(11)$ & $89(10)$ & NS \\
\hline Systemic vascular resistance (dyne.s. $\mathrm{cm}^{-5} \cdot \mathrm{m}^{2}$ ) & $2423(399)$ & $2557(585)$ & NS \\
\hline
\end{tabular}

Values are means (SD). LVEDP, left ventricular end diastolic pressure. resistance, and pulmonary vascular resistance were determined by the standard formula. Mitral valve area was calculated according to Gorlin's formula.

\section{BLOOD SAMPLING}

Blood samples were obtained from catheters in the femoral vein, pulmonary artery, left atrium, and aorta. Blood was immediately transferred into chilled glass tubes containing disodium EDTA $(1 \mathrm{mg} / \mathrm{ml})$ and aprotinin $(500 \mathrm{U} / \mathrm{ml})$ for measurement of plasma adrenomedullin, ANF, and BNP concentrations. Blood was centrifuged immediately at $4^{\circ} \mathrm{C}$ and the plasma was frozen and stored at $-80^{\circ} \mathrm{C}$ until assayed. Controls were age and sex matched normotensive subjects ( $\mathrm{n}=50,28$ males, 22 females; age 50 (10) years) with no history of hypertension and no evidence of cardiac disease. Their blood samples were obtained through the antecubital vein. In 10 of the 23 patients, venous blood samples were obtained again through the antecubital vein at one week after PTMC.

All the peptide measurements were from plasma.

ASSAY FOR PLASMA CONCENTRATIONS OF

ADRENOMEDULLIN

Stored plasma samples were extracted before radioimmunoassay. Sep-Pak C18 cartridges (Millipore-Waters, Milford, Massachusetts, USA) were prewashed sequentially with $5 \mathrm{ml}$ each of chloroform, methanol, $50 \%$ acetonitrile containing $0.1 \%$ trifluoroacetic acid (TFA), $0.1 \%$ TFA, and saline. Plasma $2 \mathrm{ml}$ was acidified with $24 \mu \mathrm{l}$ of $1 \mathrm{~mol} / \mathrm{l} \mathrm{HCl}$, and diluted with $2 \mathrm{ml}$ of saline, and then loaded onto a Sep-Pak C18 cartridge. After being washed with $5 \mathrm{ml}$ each of saline, $0.1 \%$ TFA, and $20 \%$ acetonitrile containing $0.1 \%$ TFA, the absorbed materials were eluted with $4 \mathrm{ml}$ of $50 \%$ acetonitrile containing $0.1 \%$ TFA. The eluate was then freeze dried. The freeze dried material was dissolved in radioimmunoassay buffer and the clear solution was radioimmunoassayed. The radioimmunoassay for adrenomedullin has been reported previously. ${ }^{25}$

ASSAY FOR PLASMA CONCENTRATIONS OF ANF AND BNP

Plasma concentrations of $\mathrm{ANF}$ and BNP were measured with Shiono ANP and BNP radioimmunoassay kits (Shionogi Co, Osaka, Japan), as previously reported. ${ }^{26}$

\section{STATISTICAL ANALYSIS}

Data are expressed as mean (SD). Student's unpaired $t$ test was used to evaluate differences between normal subjects and patients with mitral stenosis. Student's paired $t$ test was used to compare the plasma concentrations of adrenomedullin between the pulmonary artery and the left atrium as well as the plasma concentrations of ANF and BNP between the vein and the pulmonary artery. Plasma adrenomedullin, ANF, and BNP before and after PTMC were also evaluated by the Student paired $t$ test. A p value less than 0.05 was considered significant. Correlation 

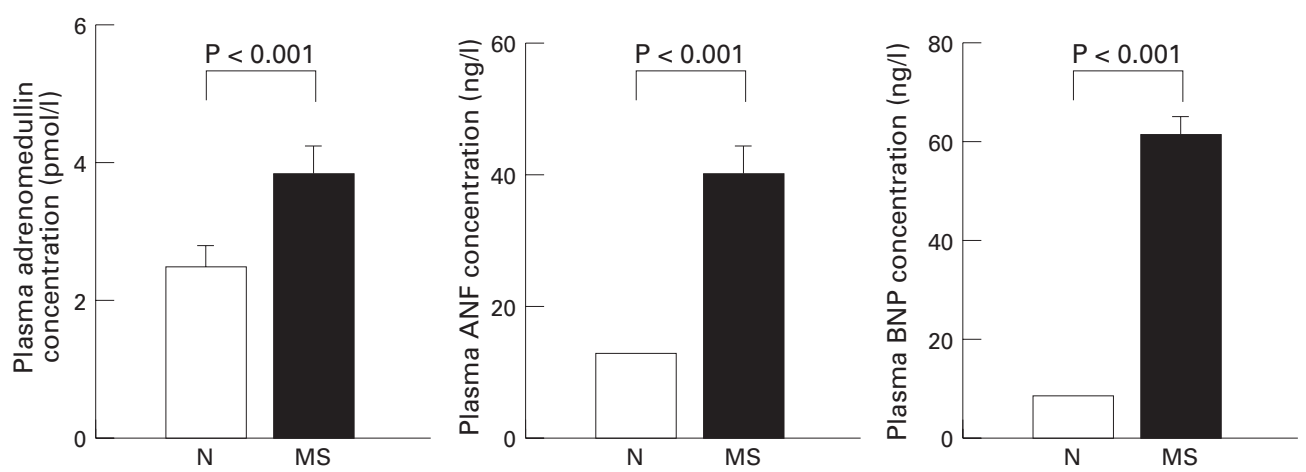

Figure 1 Venous plasma concentrations of adrenomedullin, atrial natriuretic factor ( $A N F)$, and brain natriuretic peptide $(B N P)$ in normal controls $(N)$ and patients with mitral stenosis (MS). Values are means, error bars $=S E M$

cefficients were calculated by linear regression analysis.

\section{Results}

HAEMODYNAMIC CHARACTERISTICS BEFORE AND AFTER PTMC

Haemodynamic variables before and after PTMC are presented in table 2. After PTMC, mean pulmonary artery pressure, left atrial pressure, and total pulmonary vascular resistance decreased significantly, and the mitral valve area increased significantly, whereas left ventricular end diastolic pressure, pulmonary vascular resistance, cardiac index, heart rate, mean arterial pressure, and systemic vascular resistance did not show any significant changes.

PLASMA CONCENTRATIONS OF ADRENOMEDULLIN Venous plasma concentrations of adrenomedullin were higher in patients with mitral stenosis than in age matched normal controls (fig 1). There were no differences in adrenomedullin concentrations in either between the femoral vein and pulmonary artery or between the left atrium and aorta (fig 2). However, the adrenomedullin concentrations were significantly reduced in the left atrium compared with the pulmonary artery (fig 2 ). Venous and arterial concentrations of adrenomedullin did not change 20 minutes after PTMC (vein: $3.9(1.2)$ to $3.8(1.2) \mathrm{pmol} / 1$, artery: $3.4(1.3)$ to $3.4(0.9) \mathrm{pmol} / \mathrm{l}, \mathrm{NS})$. However, in 10 of 23 patients, venous adrenomedullin concentrations decreased at one week after PTMC (from $4.1(0.6)$ to $3.7(0.6) \mathrm{pmol} / \mathrm{l}, \mathrm{p}<0.05)$.

RELATION BETWEEN PLASMA CONCENTRATIONS OF ADRENOMEDULLIN AND HAEMODYNAMIC VARIABLES

Correlations between venous concentrations of adrenomedullin and haemodynamic variables are shown in table 3 . There were significant relations between adrenomedullin and mean pulmonary artery pressure, mean left atrial pressure, mitral valve area, total pulmonary resistance, and pulmonary vascular resistance. Scatterplots of adrenomedullin in relation to pulmonary vascular resistance, total pulmonary resistance, and mean pulmonary artery pressure, which showed highly significant correlations, are presented in fig 3. Adrenomedullin also correlated with ANF and BNP (table 3). In contrast, no significant relations were observed between the adrenomedullin and the left ventricular end diastolic pressure, cardiac index, mean arterial pressure, or systemic vascular resistance.

PLASMA CONCENTRATIONS OF ANF AND BNP Venous concentrations of ANF and BNP were significantly higher in patients with mitral stenosis than in normal subjects (fig 1). ANF and BNP concentrations were significantly higher in the pulmonary artery than in the pulmonary vein (fig 2). ANF decreased 20
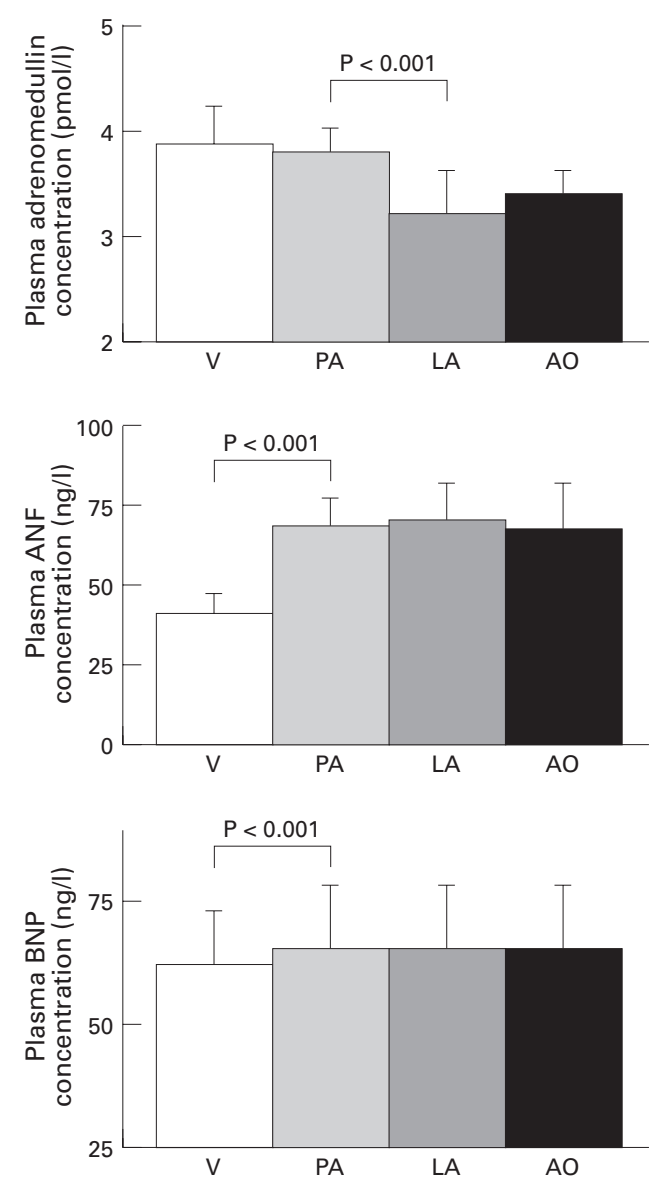

Figure 2 Plasma concentrations of adrenomedullin, atrial natriuretic factor $(A N F)$, and brain natriuretic peptide $(B N P)$ in femoral vein $(V)$, pulmonary artery $(P A)$, left atrium (LA), and aorta $(A O)$ in patients with mitral stenosis $(M S)$. Values are means, error bars $=S E M$. 
Table 3 Relations between plasma concentration of adrenomedullin and haemodynamic variables

\begin{tabular}{lll}
\hline Variable & $\begin{array}{l}\text { Correlation } \\
\text { coefficient }(r)\end{array}$ & p value \\
\hline Mean pulmonary artery pressure $(\mathrm{mm} \mathrm{Hg})$ & 0.648 & 0.001 \\
Left atrial pressure $(\mathrm{mm} \mathrm{Hg})$ & 0.547 & 0.01 \\
Mitral valve area $\left(\mathrm{cm}^{2}\right)$ & 0.432 & 0.05 \\
Total pulmonary resistance $\left(\right.$ dyne.s. $\left.\mathrm{cm}^{-5} \cdot \mathrm{m}^{2}\right)$ & 0.825 & 0.0001 \\
Pulmonary vascular resistance $\left(\right.$ dyne.s. $\left.\mathrm{cm}^{-5} \cdot \mathrm{m}^{2}\right)$ & 0.646 & 0.001 \\
Mean arterial pressure $(\mathrm{mm} \mathrm{Hg})$ & 0.091 & $\mathrm{NS}$ \\
Atrial natriuretic factor $(\mathrm{ng} / \mathrm{l})$ & 0.543 & 0.01 \\
Brain natriuretic peptide $(\mathrm{ng} / \mathrm{l})$ & 0.456 & 0.05 \\
\hline
\end{tabular}
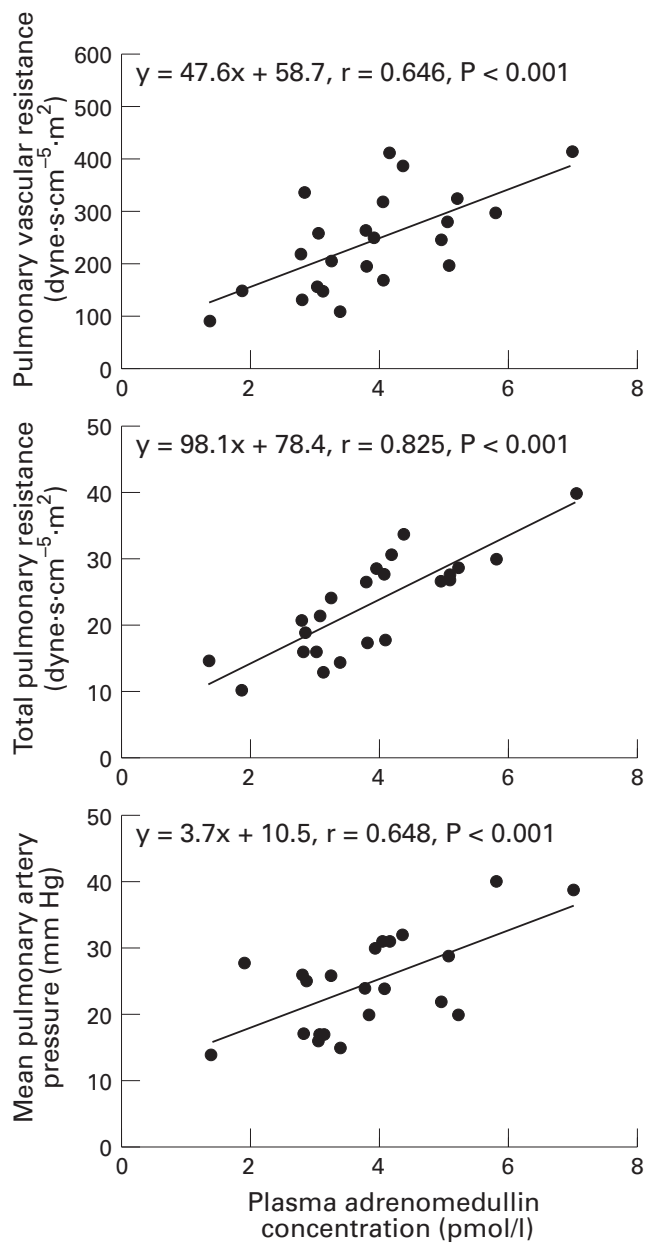

Figure 3 Scatterplots showing the relations between venous plasma adrenomedullin concentrations and pulmonary vascular resistance, total pulmonary resistance, and mean pulmonary artery pressure in patients with mitral stenosis.

minutes after PTMC, but BNP did not change (ANP, 41 (29) to 35 (24) ng/l, p < 0.05; BNP, $62(54)$ to $64(61) \mathrm{ng} / \mathrm{l}, \mathrm{NS})$. In 10 of 23 patients, ANF and BNP decreased significantly at one week after PTMC (ANF, 58 (38) to 30 (13) ng/l, p < 0.001; BNP, 88 (60) to 49 (45) ng/l, p < 0.001).

\section{Discussion}

Our study showed that venous concentrations of adrenomedullin were increased in patients with mitral stenosis compared with age matched normal controls, and there was a significant reduction in adrenomedullin from the pulmonary artery to the left atrium. Venous concentrations of adrenomedullin were corre- lated with the pulmonary artery pressure, pulmonary vascular resistance, and total pulmonary resistance. Adrenomedullin concentrations decreased significantly one week after PTMC. The results suggest the possible involvement of adrenomedullin in the pathophysiology of secondary pulmonary hypertension due to mitral stenosis.

ADRENOMEDULLIN IN MITRAL STENOSIS: POTENTIAL STIMULI AND PRODUCTION SITE Many biological effects of adrenomedullin have been reported. ${ }^{27}{ }^{28}$ In particular, it has been shown to reduce the pulmonary artery pressure and increase pulmonary blood flow by decreasing pulmonary vascular resistance. ${ }^{18} 192930$ These results suggest that it may be involved in the regulation of the cardiovascular system, including the pulmonary circulation. Indeed, increased plasma adrenomedullin has been reported in patients with pulmonary hypertension and correlated with severity of the disorder. ${ }^{17}$

The stimulation of adrenomedullin production has been attributed to increased sympathetic nerve activity and body fluid volume in patients with hypertension, chronic renal failure, and heart failure. ${ }^{2}{ }^{4}$ Our present findings of significant relations between plasma adrenomedullin and plasma $\mathrm{ANF}$ and BNP in patients with mitral stenosis are consistent with previous reports. According to a report on the genomic structure of the human adrenomedullin gene, ${ }^{31}$ the 5 '-flanking region contains multiple binding sites for activator protein-2 (AP-2) and cyclic adenosine monophosphate (cAMP) regulated enhancer elements, suggesting that the expression of the adrenomedullin gene may be subject to the activity of protein kinase $\mathrm{C}$ and cAMP concentrations. Because plasma noradrenaline is increased in mitral stenosis $^{20}$ and noradrenaline is known to activate protein kinase $\mathrm{C}$ and phospholipase $\mathrm{C}$ through the $\alpha_{1}$ receptor, increased noradrenaline concentrations in mitral stenosis may partly affect the gene expression of adrenomedullin through the $\alpha_{1}$ receptor.

The sites of production for circulating adrenomedullin have not been identified. An early report showed that adrenomedullin mRNA was highly expressed in the adrenal gland, heart, kidney, and lung. ${ }^{1}$ Sugo et $a l^{12}$ reported that vascular endothelial cells actively synthesise and secrete adrenomedullin. They showed that the expression of adrenomedullin mRNA in cultured endothelial cells was 20 -fold to 40 -fold higher than in the adrenal gland or in other tissues, and that the rate of secretion of adrenomedullin from cultured vascular endothelial cells resembled that of endothelin-1. Sugo et $a l^{13}$ also showed that cytokines such as tumour necrosis factor $\alpha$ and interleukin-1 markedly increased the expression of adrenomedullin mRNA in cultured vascular smooth muscle cells. These results suggest that the systemic vascular wall is a potential site of adrenomedullin production even in patients with mitral stenosis. In this study, plasma adrenomedullin increased between the aorta and the femoral vein. This is 
consistent with adrenomedullin production in the peripheral circulation. In addition, previous investigators described the immunohistochemical presence and distribution of adrenomedullin in the human heart and showed that adrenomedullin immunoreactivity was more intense in the ventricular myocytes of severely failing hearts than in normal hearts. ${ }^{3}$ They suggested that the heart may produce significant amounts of adrenomedullin in severe failure and is a potential site for the circulating adrenomedullin. Shimokubo et al reported increased adrenomedullin concentrations and mRNA expression in the hypertrophied right ventricle in experimentally induced pulmonary hypertension, supporting this idea. ${ }^{16} \mathrm{~A}$ recent report on adrenomedullin concentrations in the coronary sinus has shown that the heart actually secretes adrenomedullin in severe failure; however, the secretion rate of adrenomedullin is much lower than that of ANF. ${ }^{32}$ Our present study showed no increase in plasma adrenomedullin between the pulmonary vein and the pulmonary artery in patients with mitral stenosis, although there was a significant increase in plasma ANF and BNP. Thus the secretion of adrenomedullin from the heart may not contribute greatly to circulating adrenomedullin concentrations in mitral stenosis, although we cannot exclude the possibility that a small amount of adrenomedullin may be produced in the heart.

ROLE OF ADRENOMEDULLIN IN THE PULMONARY CIRCULATION

We found a significant reduction in plasma adrenomedullin between the pulmonary artery and the left atrium. This supports the findings of a previous report, showing a significant decrease in plasma adrenomedullin after the blood had circulated through the lungs in human subjects. ${ }^{14}$ Furthermore, Owji et al, ${ }^{33}$ using a receptor binding assay technique, reported an abundance of adrenomedullin binding sites in the lungs and heart of rats. They showed that the binding site in the lung was adrenomedullin specific, whereas the binding site in the heart was inhibited by CGRP or islet amyloid polypeptide. Eguchi et $a l^{7}$ and Ishizaka et $a l^{8}$ reported that vascular smooth muscle cells contain adrenomedullin specific receptors and that adrenomedullin increased intracellular cAMP in vascular smooth muscle cells. Adrenomedullin has been shown to reduce pulmonary artery pressure by decreasing the pulmonary vascular resistance, ${ }^{18} 2930$ partially mediated by nitric oxide, ${ }^{34}{ }^{35}$ In the present study, we observed significant relations between the plasma concentrations of adrenomedullin and the pulmonary artery pressure, pulmonary vascular resistance, and total pulmonary resistance. Taken together, these findings suggest that specific adrenomedullin binding sites in the pulmonary vasculature are present and that adrenomedullin may be involved in the defence mechanism against further increases in pulmonary arterial pressure in patients with mitral stenosis.
Venous and arterial concentrations of adrenomedullin did not change 20 minutes after the PTMC. It has been reported that adrenomedullin is secreted mainly from the vascular wall without being stored, and the amount of secretion depends on its genomic expression. ${ }^{12}$ Twenty minutes may therefore be too short to observe a decrease in adrenomedullin following the changes in haemodynamics after PTMC. However, plasma adrenomedullin significantly decreased one week after PTMC in a relatively severe subgroup of 10 of the 23 patients. These findings are consistent with the previous report showing that plasma adrenomedullin decreased after treatment in patients with heart failure. ${ }^{4}$ Thus adrenomedullin may respond to the changes in haemodynamics as a relatively slow regulating factor in the pulmonary circulation.

ANF AND BNP BEFORE AND AFTER PTMC IN PATIENTS WITH MITRAL STENOSIS

$\mathrm{ANF}$ and BNP circulate in the blood and play important roles in the regulation of body fluid volume and systemic and pulmonary vascular resistance in various disorders. ${ }^{36-39}$ Plasma $\mathrm{ANF}$ and BNP concentrations were higher in patients with mitral stenosis than in age matched normal controls, and there was a significant increase in these peptides between the pulmonary vein and the pulmonary artery. Thus our observation confirmed the previous findings that $\mathrm{ANF}$ and $\mathrm{BNP}$ are secreted from the heart through the coronary sinus ${ }^{40} 41$ and that both are increased in mitral stenosis. ${ }^{42}$ In our present study, by 20 minutes after PTMC there was a decrease in ANF, with a concomitant decrease in left atrial pressure and pulmonary artery pressure, whereas BNP did not change significantly. Consistent with these observations, previous reports have shown that ANP decreased after PTMC, with a concomitant fall in left atrial pressure, ${ }^{23}$ and that BNP did not change 20 minutes after PTMC. ${ }^{42}$ The primary stimulus for BNP secretion in patients with heart failure was reported to be of left ventricular origin; however, left ventricular function assessed by echocardiography was within the normal range, and left ventricular end diastolic pressure was not increased in our present study. The increased plasma concentrations of BNP may have been a reflection of right ventricular dysfunction due to the presence of secondary pulmonary hypertension. In support of this, high plasma BNP concentrations have been reported in experimentally induced pulmonary hypertension. ${ }^{43}$ Further studies are required to identify the origin of BNP in mitral stenosis and the relation between BNP and pulmonary hypertension.

\section{CONCLUSIONS}

Venous concentrations of adrenomedullin were increased in patients with mitral stenosis compared with normal controls, and significant relations between the peptide concentrations and the mean pulmonary artery pressure, pulmonary vascular resistance, and total pulmonary resistance were observed. These findings 
suggest the involvement of adrenomedullin in the pathophysiology of pulmonary hypertension in patients with mitral stenosis. However, there was no direct evidence for a functional role of adrenomedullin in the control of the pulmonary circulation in this disorder. Further studies are required to clarify the functional roles of adrenomedullin in the pulmonary circulation in both physiological and pathophysiological conditions.

This work was supported in part by special coordination funds for promoting science and technology (Encouragement System of COE) from the Science and Technology Agency of Japan, the Ministry of Health and Welfare, and the Human Science Foundation of Japan. We thank Ms Yoko Saito for her technical assistance.

1 Kitamura $\mathrm{K}$, Kangawa $\mathrm{K}$, Kawamoto $\mathrm{M}$, Ichiki $\mathrm{Y}$, Nakamura S, Matsuo $\mathrm{H}$, et al. Adrenomedullin: a novel hypotensive peptide isolated from human pheochromocy-
toma. Biochem Biophys Res Commun 1993;192:553-60.

2 Ishimitsu T, Nishikimi T, Saito Y, Kitamura K, Eto T, Kangawa $\mathrm{K}$, et al. Plasma levels of adrenomedullin, a hypotensive peptide, in patients with hypertension and renal sive peptide, in patients with hyperter

3 Jougasaki M, Wei C, McKinley LJ, Burnett JC. Elevation of circulating and ventricular adrenomedullin in human congestive heart failure. Circulation 1995;92:286-9.

4 Nishikimi T, Saito Y, Kitamura K, Ishimitsu T, Eto T, Kangawa $\mathrm{K}$, et al. Increased plasma levels of adrenomedullin in patients with heart failure. $\mathcal{f} \mathrm{Am}$ Coll Cardiol 1995;26: 1424-31.

5 Kato J, Kobayashi K, Etoh T, Tanaka M, Kitamura K, Imamura $\mathrm{T}$, et al. Plasma adrenomedullin concentration in patients with heart failure. 7 Clin Endocrinol Metab 1996;81:180-3.

6 Tanaka M, Kitamura K, Ishizaka Y, Ishiyama Y, Kato J, Kangawa $\mathrm{K}$, et al. Plasma adrenomedullin in various diseases and exercise-induced change in adrenomedullin in healthy subjects. Intern Med 1995;35:728-33.

7 Eguchi S, Hirata Y, Kano H, Sato K, Watanabe Y, Watanabe $\mathrm{X}$, et al. Specific receptors for adrenomedullin in cultured rat vascular smooth muscle cells. FEBS Lett 1994;340:22630 .

8 Ishizaka Y, Ishizaka Y, Tanaka M, Kitamura K, Kangawa K, Minamino N, et al. Adrenomedullin stimulates cyclic AMP formation in rat vascular smooth muscle cells. Biochem Biophys Res Commun 1994;200:642-6.

9 Feng CJ, Kang B, Kaye AD, Kadowitz PJ, Nossaman BD. L-NAME modulates response to adrenomedullin in the hindquarters vascular bed of the rat. Life Sci 1994;55:4338.

10 Majid DS, Kadowitz PJ, Coy DH, Navar LG. Renal response to intra-arterial administration of adrenomedullin in dogs. Am F Physiol 1996;270:F200-5.

11 Nakamura M, Yoshida H, Arakawa N, Makita S, Niinuma $\mathrm{H}$, Hiramori $\mathrm{K}$. The vasodilatory potency of adrenomedullin in human forearm vascular bed. Circulation 1997;95: 1214-21.

12 Sugo S, Minamino N, Kangawa K, Miyamoto K, Kitamura $\mathrm{K}$, Sakata J, et al. Endothelial cells actively synthesize and secrete adrenomedullin. Biochem Biophys Res Commun 1994;201:1160-6.

13 Sugo S, Minamino N, Shoji H, Kangawa K, Kitamura K, Eto $\mathrm{T}$, et al. Production and secretion of adrenomedullin from vascular smooth muscle cells: augmented production by tumor necrosis factor $\alpha$. Biochem Biophys Res Commun 1994;203:719-26.

14 Nishikimi T, Kitamura K, Saito Y, Shimada K, Ishimitsu T, Takamiya $\mathrm{M}$, et al. Clinical studies for the sites of production and clearance of circulating adrenomedullin in human subjects. Hypertension 1994;24:600-4.

15 Kapas S, Catt KJ, Clark AJL. Cloning and expression of cDNA encoding a rat adrenomedullin receptor. 7 Biochen 1995;270:25344-7.

16 Shimokubo T, Sakata J, Kitamura K, Kangawa K, Matsuo $\mathrm{H}$, Eto $\mathrm{T}$. Augmented adrenomedullin concentrations in right ventricle and plasma of experimental pulmonary hypertension. Life Sci 1995;57:1771-9.

17 Yoshibayashi M, Kamiya T, Kitamura K, Saito Y, Kangawa $\mathrm{K}$, Matsuo $\mathrm{H}$, et al. Plasma levels of adrenomedullin in primary and secondary hypertension in patients $<20$ years of mary and secondary hypertension in

18 Lippton H, Chang JK, Hao Q, Summer W, Hyman A Adrenomedullin dilates the pulmonary vascular bed in vivo. $\mathcal{F}$ Appl Physiol 1994;76:2154-6.

19 Heaton J, Lin B, Chang JK, Steinberg S, Hyman A, Lippton $\mathrm{H}$. Pulmonary vasodilation to adrenomedullin: a nove peptide in humans. Am f Physiol 1995;268 (Heart Circ Physiol 37): $\mathrm{H} 2211-15$

20 Tsuchihashi K, Sawai N, Takizawa H, Takahashi N, Ishiguro $\mathrm{T}$, Hikita $\mathrm{N}$, et al. Plasma noradrenaline as an indicator of functional state in hearts with mitral stenosis: he influence of acutely reduced left atrial pressure by balloon mitral commissurotomy. Heart Vessels 1993;8:85-99.

21 Kinoshita O, Yoshimi H, Nagata S, Ishikura F, Kimura K, Yamabe $\mathrm{T}$, et al. Rapid increase in plasma endothelin concentrations during percutaneous balloon dilatation of the mitral valve in patients with mitral stenosis. Br Heart $\mathcal{f}$ 1993;69:322-6.

22 Yamamoto K, Ikeda U, Mito H, Fujikawa H, Sekiguchi H, Shimada K. Endothelin production in pulmonary circulation of patients with mitral stenosis. Circulation 1994;89: 2093-8.

23 Ishikura F, Nagata S, Hirata Y, Kimura K, Nakatani S, Tamai J, et al. Rapid reduction of atrial natriuretic peptide levels during percutaneous transvenous mitral commissurotomy in patients with mitral stenosis. Circulation 1989; 79:47-50.

24 Yasuda S, Nagata S, Tamai J, Ishikura F, Yamabe T, Kimura $\mathrm{K}$, et al. Left ventricular pressure-volume response mmediately after successful percutaneous mitral commissurotomy. Am 7 Cardiol 1993;71:932-7.

25 Kitamura K, Ichiki Y, Tanaka M, Kawamoto M, Emura J, Sakakibara S, et al. Immunoreactive adrenomedullin in human plasma. FEBS Lett 1994;341:288-90.

26 Yasue H, Yoshimura M, Shimada H, Kikuta K, Kugiyama $\mathrm{K}$, Jougasaki $\mathrm{M}$, et al. Localization and mechanism of secretion of B-type natriuretic peptide in comparison with those of A-type natriuretic peptide in normal subjects and patients with heart failure. Circulation 1994;90:195-203.

27 Jougasaki $M$, Wei CM, Aarhus AA, Heublein DM, Sandberg SM, Burnett JC. Renal localization and actions of adrenomedullin: a natriuretic peptide. Am $\mathcal{f}$ Physiol 1995;268:F657-63.

28 Ebara T, Miura K, Okumura M, Matsuura T, Kim S, Yukimura $\mathrm{T}$, et al. Effect of adrenomedullin on renal hemodynamics and function in dogs. Eur $\mathcal{F}$ Pharmacol 1994;263: $69-73$.

29 Cheng DY, Dewitt BJ, Wegmann MJ, Coy DH, Bitar K, Murphy WA, et al. Synthetic human adrenomedullin and ADM 15-52 have potent short-lasting vasodilator activity in the pulmonary vascular bed of the cat. Life Sci 1994;55: 251-6.

30 Nossaman BD, Feng CJ, Cheng DY, Dewitt BJ, Coy DH, Murphy WA, et al. Comparative effects of adrenomedullin, an adrenomedullin analog, and CGRP in the pulmonary vascular bed of the cat and rat. Life Sci 1995;56:63-6.

31 Ishimitsu T, Kojima M, Kangawa K, Hino J, Matsuoka H, Kitamura K, et al. Genomic structure of adrenomedullin gene. Biochem Biophys Res Commun 1994;203:631-9.

32 Jougasaki M, Rodeheffer RJ, Redfield MM, Yamamoto K, Wei C, McKinley LJ, et al. Cardiac secretion of adrenomedullin in human heart failure. $\mathcal{F}$ Clin Invest 1996;97:2370-

33 Owji AA, Smith DM, Coppock HA, Morgan DGA, Bhogal $\mathrm{R}$, Ghatei MA, et al. An abundant and specific binding site for the novel vasodilator adrenomedullin in the rat. Endocrinology 1995;136:2127-34.

34 Nossaman BD, Feng CJ, Kaye AD, Dewitt B, Coy DH, Murphy WA, et al. Pulmonary vasodilator response to adrenomedullin are reduced by NOS inhibitors in rats but not in cats. Am f Physiol 1996;270:L782-9.

35 Shimoike Y, Nagata K, Ohta S, Kambayashi Y, Teraoka H, Kitamura K, et al. Adrenomedullin stimulates two signal transduction pathways, cAMP accumulation and $\mathrm{Ca}^{2+}$ mobilization, in bovine aortic endothelial cells. $f$ Biol Chem 1995;270:4412-17.

36 Tsutamoto T, Kanamori T, Wada A, Kinoshita M. Uncoupling of atrial natriuretic peptide extraction and cyclic guanosine monophosphate production in the pulmonary circulation in patients with severe heart failure. $7 \mathrm{Am}$ Coll Cardiol 1992;20:541-6.

37 Barer G, Emery C, Stewart A, Bee D, Howard P. Endothelial control of the pulmonary circulation in normal and chronically hypoxic rats. F Physiol (Lond) 1993;463:1-16.

38 Cargill RI, Lipworth BJ. Pulmonary vasorelaxant activity of atrial natriuretic peptide and brain natriuretic peptide in humans. Thorax 1995;50:183-5.

39 Klinger JR, Petit RD, Curtin LA, Warburton RD, Wrenn $\mathrm{DS}$, Steinhelper ME, et al. Cardiopulmonary responses to chronic hypoxia in transgenic mice that overexpress ANP. $\mathcal{F}$ Appl Physiol 1993;75:198-205.

40 Sugawara A, Nakao K, Morii N, Sakamoto M, Suga M, Shimokura $\mathrm{M}$, et al. Human atrial natriuretic polypeptide is released from heart and circulates in the body. Biochem Biophys Res Commun 1985;129:439-46.

41 Mukoyama M, Nakao K, Hosoda K, Suga S, Saito Y, Ogawa $\mathrm{Y}$, et al. Brain natriuretic peptide as a novel cardiac hormone in humans. 7 Clin Invest 1991;87:1402-12.

42 Tharaux PL, Dussaule JC, Hubert-Brierre J, Vahanian A, Acar J, Ardaillou R. Plasma atrial and brain natriuretic peptides in mitral stenosis treated by valvulotomy. Clin Sci 994;87:671-7.

43 Hill NS, Klinger JR, Warburton RR, Pietras L, Wrenn DS. Brain natriuretic peptide: possible role in the modulation of hypoxic pulmonary hypertension. Am F Physiol 1994;266: L308-15. 